\title{
Chemotherapy during the last 30 days of life and the role of palliative care referral, a single center experience
}

\author{
Indryas Woldie ${ }^{1 *}$, Tarek Elfiki ${ }^{1}$, Swati Kulkarni ${ }^{1}$, Colvin Springer ${ }^{1}$, Eric McArthur ${ }^{2}$ and Nicole Freeman ${ }^{1}$
}

\begin{abstract}
Background: Chemotherapy use closer to the end of life is a marker of poor-quality care. There are now multiple studies and local reviews addressing this issue. Understanding the practice locally will give valuable insight and opportunity for improvement.
\end{abstract}

Methods: The study is a retrospective chart review of patients on chemotherapy at the Windsor Regional Cancer Center who died between April 15t, 2016 to December 31 3 , 2018. Information on demographics, type of cancer, type, intent and route of chemotherapy, line of chemotherapy, referral to hospice and palliative care services was collected.

Results: A total of 681 patients on chemotherapy died between April $1^{\text {st }}, 2016$ to Dec $13^{\text {th }}, 2018$. Of these, 119 (17.4 $\%$ died within 30 days following chemotherapy. Chemotherapy was parenteral (Intravenous and Subcutaneous) for the majority (75.2\%) of the patients. Most (66.4\%) of the patients died of disease progression. Intent for chemotherapy was palliative in $85 \%$ of patients, adjuvant/neoadjuvant in $6.6 \%$ and curative in $8.4 \%$ of the patients. Chemotherapy was $1^{\text {st }}, 2^{\text {nd }}, 3^{\text {rd }}$ line or more in $67.4 \%, 21.3 \%$ and $11.3 \%$ of the patients respectively. The type of chemotherapy was conventional in $74.3 \%$ of patients and targeted/immunotherapy in $25.7 \%$ of patients.

Of the variables studied, lack of palliative referral and having lung cancer or melanoma were significantly associated with higher risk of getting chemotherapy within the last 30 days of life. The odds of getting chemotherapy within the last 30 days of life was $0.35,95 \% \mathrm{Cl}(0.24-0.53), P<0.001$ for those who were referred to palliative care. On the other hand, the odds of getting chemotherapy were $4.18,95 \% \mathrm{Cl}(1.17-13.71), P=0.037$ and $2.21,95 \% \mathrm{Cl}(1.24-4.01), P=$ 0.037 for those with melanoma and lung cancer respectively. In addition, those with early referral to palliative care (90 days or more prior to death) were least likely to receive chemotherapy within the last 30 days of life.

Conclusion: Administration of chemotherapy within the last 30 days of life could cause unnecessary suffering to patients and cost to society. Early referral to palliative care was significantly associated with reduced risk of getting chemotherapy within the last 30 days of life in this study. Prospective study is recommended to further investigate the role of early palliative referral on use of chemotherapy during the last 30 days of life.

Keywords: Chemotherapy, Palliative care, End of life

*Correspondence: Indryas.woldie@wrh.on.ca

${ }^{1}$ Windsor Regional Hospital, 2220 Kildare, WRCC, Windsor, ON N8W 2X3, Canada

Full list of author information is available at the end of the article

\section{Introduction}

Chemotherapy use closer to the end of life is a marker of poor-quality care. It is a complex decision-making process that involves patient, family, oncologist and other members of the cancer care team. Chemotherapy at the 
end of life could decrease survival and increase health care utilization according to some studies [1-4].

Although the role of effective communication and involvement of palliative care has been emphasized as a solution, studies have shown considerable variation in transition from active therapy to end of life care [5]. A study from the United States showed many oncologists were reluctant to prescribe chemotherapy at the end of life. On the other hand, a patient's decision depends on the clarity of information $\mathrm{s} /$ he receive [6].

A study from France showed patients who died in for profit hospitals, comprehensive cancer centers and centers without palliative care had greater than average use of chemotherapy near the end of life [7]. Very high rates of chemotherapy in the last 30 days of life were noticed in centers with no or limited palliative care services as well [8].

Another critical issue is the accuracy of oncologists' predictions of survival. A study found out that oncologists made accurate predictions of survival in around a third of patients [9]. Finally, the role of chemotherapy in palliating symptoms should also be taken into account. This is especially true with the newer targeted and immunotherapeutic agents that are convenient to administer, could work quickly to palliate symptoms, and could be used more and more in the future [10].

This retrospective study will describe the rate of chemotherapy administered within the last 30 days of life and associated factors at a regional cancer center in Ontario, Canada. The study is unique as it gathered information on timing of palliative care referral both from the time of diagnosis as well as time of death and its relation to chemotherapy around the end of life.

\section{Methods}

The study is a retrospective chart review of 681 patients on chemotherapy at the Windsor Regional Cancer Center who died between April $1^{\text {st }}, 2016$ and December $31^{\text {st }}$, 2018 per hospital records. Chemotherapy was defined as conventional/cytotoxic/, targeted therapy and immunotherapy based on the last chemotherapy regimen preceding patient's death. Patients receiving hormonal therapy as the only cancer treatment were excluded. Information on demographics, type of cancer, type, intent and route of chemotherapy, line of chemotherapy and referral to palliative care services was collected. Additional information on time from diagnosis to palliative care referral as well as palliative care referral to death was also collected. Palliative care referral was considered early if patient was referred 90 days or more prior to death. These variables were selected during the inception of the study by the investigators based on their clinical judgment. Ethical clearance was obtained from the ethics review board of the Windsor Regional Hospital.

Continuous variables were presented as median (interquartile range) and categorical variables were presented as frequency (percentage). Univariable associations for factors of interest were estimated using odds ratios and their associated 95\% confidence intervals, obtained from logistic regression models. Twosided $p$-values $<0.05$ were considered statistically significant.

\section{Results}

A total of 681 patients on chemotherapy died between April $1^{\text {st }}, 2016$ to Dec $31^{\text {st }}, 2018$. The median time for all patients from diagnosis to death was 1.73 years with an interquartile range of 0.82 to 3.46 . Of these, 119 (17.4\%) died within 30 days following chemotherapy, with a median of 17 days (range 1-30 days). Of those who died within 30 days of chemotherapy: $55.5 \%$ were male with a median age of 69 years. Intent for chemotherapy was palliative in $89.9 \%$ of patients, curative in $6.7 \%$ of the patients and adjuvant/neoadjuvant in $3.4 \%$. Chemotherapy was $1^{\text {st }}, 2^{\text {nd }}, 3^{\text {rd }}$ line or more in $70.6 \%$, $16 \%$ and $13.4 \%$ of the patients respectively. The type of chemotherapy was conventional in $73.9 \%$ of the patients and targeted/immunotherapy in $26.1 \%$ of patients. Oral chemotherapy was used in a third $(29.4 \%)$ of the patients, while the rest was parenteral (Intravenous or Subcutaneous). The three most common types of cancer in those patients who died within 30 days following chemotherapy were lung (30.3\%), hematologic (22.7\%) and gastro-intestinal (18.5\%). Only $44.5 \%$ of the patients who died within 30 days of chemotherapy were referred to palliative care. Of these; $26 \%, 23.8 \%$ and $15.4 \%$ were referred within one year, 1-3 years and $>3$ years of diagnosis respectively. On the other hand, $38 \%$ of those referred to palliative care, were referred 90 days or more prior to death which is considered as early referral in this study (Table 1 ).

Almost half (49\%) of the patients died in the hospital, whereas $15.5 \%$ passed away in hospice and $15.5 \%$ died at home. Place of death was unknown for $20 \%$ of patients.

Of the variables evaluated, referral to palliative care and type of cancer were significantly associated with the likelihood of receiving chemotherapy during the last 30 days of life. Patients who were referred to palliative care were less likely to receive chemotherapy within the last 30 days of their life [OR 0.35 , 95\% CI (0.24-0.53), $P<0.001]$. In addition, those who had early referral to palliative care (referral 90 days or more prior to death) were least likely to receive 
Table 1 Baseline characteristics of study subjects

\begin{tabular}{|c|c|c|c|}
\hline & \multirow[b]{2}{*}{$\begin{array}{l}\text { Overall } \\
(\mathrm{N}=681)\end{array}$} & \multicolumn{2}{|c|}{ Death within 30 days } \\
\hline & & $\begin{array}{c}\text { Yes } \\
(N=119)\end{array}$ & $\begin{array}{c}\text { No } \\
(N=562)\end{array}$ \\
\hline \multicolumn{4}{|l|}{ Age, years } \\
\hline Median (IQR) & $68(59,75)$ & $69(62,75)$ & $68(59,75)$ \\
\hline \multicolumn{4}{|l|}{ Gender } \\
\hline Female & $307(45.1 \%)$ & $53(44.5 \%)$ & $254(45.2 \%)$ \\
\hline Male & $374(54.9 \%)$ & $66(55.5 \%)$ & $308(54.8 \%)$ \\
\hline \multicolumn{4}{|l|}{ Cancer site } \\
\hline Breast & $70(10.3 \%)$ & $9(7.6 \%)$ & $61(10.9 \%)$ \\
\hline Central Nervous System & $17(2.5 \%)$ & $3(2.5 \%)$ & $14(2.5 \%)$ \\
\hline Gastrointestinal & $169(24.8 \%)$ & $22(18.5 \%)$ & $147(26.2 \%)$ \\
\hline Genitourinary & $63(9.3 \%)$ & $7(5.9 \%)$ & $56(10.0 \%)$ \\
\hline Gynecologic & $26(3.8 \%)$ & $2(1.7 \%)$ & $24(4.3 \%)$ \\
\hline Hematologic & $140(20.6 \%)$ & $27(22.7 \%)$ & $113(20.1 \%)$ \\
\hline Head and neck & $11(1.6 \%)$ & $1(0.8 \%)$ & $10(1.8 \%)$ \\
\hline Lung & $145(21.3 \%)$ & $36(30.3 \%)$ & $109(19.4 \%)$ \\
\hline Melanoma & $13(1.9 \%)$ & $5(4.2 \%)$ & $8(1.4 \%)$ \\
\hline Primary unknown & $20(2.9 \%)$ & $4(3.4 \%)$ & $16(2.8 \%)$ \\
\hline Other & $7(1.0 \%)$ & $3(2.5 \%)$ & $4(0.7 \%)$ \\
\hline \multicolumn{4}{|l|}{ Chemotherapy type } \\
\hline Conventional & $506(74.3 \%)$ & $88(73.9 \%)$ & $418(74.4 \%)$ \\
\hline Targeted/Immunotherapy & $175(25.7 \%)$ & $31(26.1 \%)$ & $144(25.6 \%)$ \\
\hline \multicolumn{4}{|l|}{ Route of administration } \\
\hline Intravenous/Subcutaneous & $512(75.2 \%)$ & $84(70.6 \%)$ & $428(76.2 \%)$ \\
\hline Oral & $169(24.8 \%)$ & $35(29.4 \%)$ & $134(23.8 \%)$ \\
\hline \multicolumn{4}{|l|}{ Palliative referral } \\
\hline Yes & $444(65.2 \%)$ & $53(44.5 \%)$ & $391(69.6 \%)$ \\
\hline No & $237(34.8 \%)$ & $66(55.5 \%)$ & $171(30.4 \%)$ \\
\hline \multicolumn{4}{|c|}{ Time from diagnosis to palliative referral } \\
\hline No referral & $237(34.8 \%)$ & $66(55.5 \%)$ & $171(30.4 \%)$ \\
\hline$<1$ year & $177(26.0 \%)$ & $29(24.4 \%)$ & $148(26.3 \%)$ \\
\hline 1 to $<3$ years & $162(23.8 \%)$ & $13(10.9 \%)$ & $149(26.5 \%)$ \\
\hline $3+$ years & $105(15.4 \%)$ & $11(9.2 \%)$ & $94(16.7 \%)$ \\
\hline \multicolumn{4}{|c|}{ Time from palliative referral to death } \\
\hline No referral & $237(34.8 \%)$ & $66(55.5 \%)$ & $171(30.4 \%)$ \\
\hline$<90$ days & $259(38.0 \%)$ & $40(33.6 \%)$ & $219(39.0 \%)$ \\
\hline $90+$ days & $185(27.2 \%)$ & $13(10.9 \%)$ & $172(30.6 \%)$ \\
\hline \multicolumn{4}{|l|}{ Intent of chemotherapy } \\
\hline Palliative & $579(85.0 \%)$ & $107(89.9 \%)$ & $472(84.0 \%)$ \\
\hline Neoadjuvant/Adjuvant & $45(6.6 \%)$ & $4(3.4 \%)$ & $41(7.3 \%)$ \\
\hline Cure & $57(8.4 \%)$ & $8(6.7 \%)$ & $49(8.7 \%)$ \\
\hline \multicolumn{4}{|l|}{ Line of chemotherapy } \\
\hline 1 & $459(67.4 \%)$ & $84(70.6 \%)$ & $375(66.7 \%)$ \\
\hline 2 & $145(21.3 \%)$ & $19(16.0 \%)$ & $126(22.4 \%)$ \\
\hline $3+$ & $77(11.3 \%)$ & $16(13.4 \%)$ & $61(10.9 \%)$ \\
\hline
\end{tabular}


chemotherapy within the last 30 days of life [0.2, 95\% CI (0.1-0.36), $P<0.001]$. On the other hand, patients who were referred to palliative care closest to diagnosis were more likely to have chemo within the last 30 days of life compared to those who were referred further from diagnosis Table 2.

With respect to cancer type, compared to gastrointestinal cancer, lung cancer $[2.21,95 \%$ CI (1.24-4.01), $P$ $=0.037]$ and melanoma [4.18, 95\% CI (1.17-13.71), $P=$ 0.037] were significantly associated with higher odds of receiving chemotherapy within the last 30 days of life (Table 2).

\section{Discussion}

The study showed $17.4 \%$ of patients died within 30 days of chemotherapy which is similar to other studies from USA, France and Taiwan, but higher than a study from Switzerland that showed only $11.7 \%$ of patients received chemotherapy in the last 4 weeks of their life [7, 11-13].

However, our results are much lower than the data from Uganda and Egypt that showed $45 \%$ and $56 \%$ of patients in these countries, respectively, received chemotherapy in their last month of life [8, 14]. A possible explanation could be limited availability of palliative care services although cultural differences in end-of-life care could

Table 2 Association between study variables and odds of receiving chemotherapy within the last 30 days of life

\begin{tabular}{|c|c|c|c|c|c|c|c|c|}
\hline \multirow{3}{*}{\begin{tabular}{|l} 
Variable \\
Age, per year
\end{tabular}} & \multirow{3}{*}{ Value } & \multirow{3}{*}{$\mathbf{N}$} & \multirow{3}{*}{$\mathbf{n}$} & \multirow{3}{*}{$\%$} & \multicolumn{4}{|c|}{ Unadjusted } \\
\hline & & & & & \multirow{2}{*}{$\begin{array}{r}\text { Odds Ratio } \\
1.01\end{array}$} & \multicolumn{2}{|c|}{$95 \% \mathrm{Cl}$} & \multirow{2}{*}{$\begin{array}{r}\text { P-value } \\
0.43\end{array}$} \\
\hline & & & & & & 0.99 & 1.02 & \\
\hline \multicolumn{9}{|l|}{ Sex } \\
\hline & Female & 307 & 53 & $17.3 \%$ & 1.00 & (referent) & & \\
\hline & Male & 374 & 66 & $17.6 \%$ & 1.03 & 0.69 & 1.53 & 0.90 \\
\hline \multicolumn{9}{|l|}{ Cancer site } \\
\hline & Breast & 70 & 9 & $12.9 \%$ & 0.99 & 0.41 & 2.20 & \multirow{11}{*}{0.037} \\
\hline & CNS & 17 & 3 & $17.6 \%$ & 1.43 & 0.31 & 4.83 & \\
\hline & GI & 169 & 22 & $13.0 \%$ & 1.00 & (referent) & & \\
\hline & Genitourinary & 63 & 7 & $11.1 \%$ & 0.84 & 0.32 & 1.98 & \\
\hline & Gynecologic & 26 & 2 & $7.7 \%$ & 0.56 & 0.09 & 2.06 & \\
\hline & Hematologic & 140 & 27 & $19.3 \%$ & 1.60 & 0.87 & 2.97 & \\
\hline & Head and neck & 11 & 1 & $9.1 \%$ & 0.67 & 0.04 & 3.75 & \\
\hline & Lung & 145 & 36 & $24.8 \%$ & 2.21 & 1.24 & 4.01 & \\
\hline & Melanoma & 13 & 5 & $38.5 \%$ & 4.18 & 1.17 & 13.71 & \\
\hline & Primary unknown & 20 & 4 & $20.0 \%$ & 1.67 & 0.45 & 5.07 & \\
\hline & Other & 7 & 3 & $42.9 \%$ & 5.01 & 0.94 & 24.23 & \\
\hline \multicolumn{9}{|l|}{ Chemo type } \\
\hline & Conventional & 506 & 88 & $17.4 \%$ & 1.00 & (referent) & & \\
\hline & Targeted/Immunotherapy & 175 & 31 & $17.7 \%$ & 1.02 & 0.64 & 1.59 & 0.92 \\
\hline \multicolumn{9}{|c|}{ Route of administration } \\
\hline & IV/subcutaneous & 512 & 84 & $16.4 \%$ & 1.00 & (referent) & & \\
\hline & Oral & 169 & 35 & $20.7 \%$ & 1.33 & 0.85 & 2.05 & 0.20 \\
\hline \multicolumn{9}{|l|}{\begin{tabular}{|l|} 
Palliative referral \\
\end{tabular}} \\
\hline & No & 237 & 66 & $27.8 \%$ & 1.00 & (referent) & & $<0.001$ \\
\hline & Yes & 444 & 53 & $11.9 \%$ & 0.35 & 0.24 & 0.53 & \\
\hline \multicolumn{9}{|c|}{ Time to palliative referral } \\
\hline & No referral & 237 & 66 & $27.8 \%$ & 1.00 & (referent) & & \multirow{4}{*}{$<0.001$} \\
\hline & $<1$ year & 177 & 29 & $16.4 \%$ & 0.51 & 0.31 & 0.82 & \\
\hline & 1 to $<3$ years & 162 & 13 & $8.0 \%$ & 0.23 & 0.12 & 0.41 & \\
\hline & $3+$ years & 105 & 11 & $10.5 \%$ & 0.30 & 0.15 & 0.58 & \\
\hline \multicolumn{9}{|c|}{\begin{tabular}{|l|l|} 
Time from referral to death & \\
\end{tabular}} \\
\hline & No referral & 237 & 66 & $27.8 \%$ & 1.00 & (referent) & & \multirow{3}{*}{$<0.001$} \\
\hline & $<90$ days & 259 & 40 & $15.4 \%$ & 0.47 & 0.30 & 0.73 & \\
\hline & $90+$ days & 185 & 13 & $7.0 \%$ & 0.20 & 0.10 & 0.36 & \\
\hline \multicolumn{9}{|c|}{ Chemotherapy intent } \\
\hline & Palliative & 579 & 107 & $18.5 \%$ & 1.00 & (referent) & & \multirow{3}{*}{0.17} \\
\hline & Neoadjuvant/adjuvant & 45 & 4 & $8.9 \%$ & 0.43 & 0.13 & 1.09 & \\
\hline & Cure & 57 & 8 & $14.0 \%$ & 0.72 & 0.31 & 1.48 & \\
\hline \multicolumn{9}{|c|}{ Line of chemotherapy } \\
\hline & 1 & 459 & 84 & $18.3 \%$ & 1.00 & (referent) & & \multirow{3}{*}{0.24} \\
\hline & 2 & 145 & 19 & $13.1 \%$ & 0.67 & 0.38 & 1.13 & \\
\hline & $3+$ & 77 & 16 & $20.8 \%$ & 1.17 & 0.63 & 2.09 & \\
\hline
\end{tabular}


also play a role. Our study also showed patients who were referred to palliative care were less likely to receive chemotherapy within the last 30 days of their life. This is further supported by a study from France that showed young individuals, those treated in comprehensive cancer centers or high-volume centers without palliative care units were the most likely to receive chemotherapy near the end of life [7]. Another multicenter study from the USA showed quality of life near death is not improved and can be harmed by chemotherapy near death even in patients with good performance status $[15,16]$.

This is an interesting paradox particularly in low resource areas with limited palliative care service resulting in the use of more expensive and potentially harmful chemotherapy with futile outcome around the end of life. This suggests the need to build palliative care services hand in hand with active therapy in cancer treatment centers.

Our study showed only referral to palliative care and type of cancer were significantly associated with the likelihood of receiving chemotherapy in the last 30 days of life. Patients who are not referred to palliative care and those with either lung cancer or melanoma were more likely to receive chemotherapy within the last 30 days of their life. Further look into the association of palliative care referral and chemotherapy around the end of life showed those with early referral to palliative care $(90$ days or more prior to death), were least likely to receive chemotherapy within the last 30 days of life.

A study in Ontario showed younger age, male gender, hematologic malignancies and breast cancer were all associated with more aggressive care, which among others includes last dose of chemotherapy within the last 14 days of life [17]. Smaller sample size in our study might be the reason for the lack of statistically significant associations for some of the variables.

The benefits of early palliative referral cannot be overemphasized as there is evidence for improved quality of life and prolonged survival in patients referred to palliative care [18]. A study from New York showed chemotherapy in the last 30 days of life was associated with an increased rate of hospital admissions, emergency department visits, death in the hospital, fewer days in hospice care and a more than $50 \%$ increase in patient out of pocket costs for care. Another study from Taiwan showed similar findings $[3,15]$. Our study also showed almost half of the patients who received chemotherapy within the last 30 days of life died in the hospital. This is partly explained by the fact that only $44 \%$ of the patients who recieved chemotherapy within the last 30 days of life were referred to palliative care.

The finding of more chemotherapy use in patients referred to palliative care closer to diagnosis in our study needs further investigation. One possible explanation could be earlier referral (from diagnosis) to palliative care for patients with more aggressive cancer who are likely to get at least first line palliative chemotherapy and die sooner). Further study, preferably prospective, incorporating ECOG performance status, reason for palliative referral and other relevant variables is recommended. We attempted to include ECOG performance status (PS) as a variable in our study, however information on PS was missing in most of the patients.

Although most studies around the use of chemotherapy closer to the end of life are retrospective, there are few prospective studies. A prospective study by Temel and colleagues showed patients receiving early palliative care who reported an accurate perception of their prognosis were less likely to receive intravenous chemotherapy near the end of life compared to those receiving standard of care $(9.4 \% v 50 \% ; P=.02)$ [19].

Finally, with the shift from conventional chemotherapy to targeted therapy with less toxicity and better efficacy is expected to change the landscape of cancer treatment making it more likely to see overlap between active therapy and palliative care [10]. However, this is not always the case particularly for those with low performance status as studies have shown no difference in survival among clinical trial ineligible patients (due to poor PS) between regular chemotherapy, chemotherapy and immunotherapy or immunotherapy alone. Another study actually showed significant toxicity from Immunotherapy [20, 21].

The study has several limitations including retrospective design; lack of details on circumstances of around the decision to stop chemotherapy which might be due to declining PS, Insurance coverage issue, patient/family decision among others; and relatively small sample size. Despite these limitations, it shed light on local practices with respect to chemotherapy use around end of life and associated factors.

\section{Conclusions}

The use of chemotherapy in the last 30 days of life could result in inconvenience and unnecessary cost to patients and the health care system. Early palliative referral (90 days or more prior to death) is associated with less use of chemotherapy around the end of life in this study and is recommended. Further prospective studies and continuous audits on end-of-life care are also recommended.

\section{Acknowledgement}

We would like to acknowledge Windsor Regional Hospital administration decision support team for facilitating data acquisition.

\section{Authors' contributions}

IW, TE and SK contributed in the conception of the study. IW, TE, SK, CS, NF contributed in data acquisition. IW, EM and NF contributed in data analysis 
and interpretation of the results. IW and EM drafted the manuscript. All authors critically reviewed the manuscript and approved with the final version.

\section{Funding}

This research received no specific grant from any funding agency in the public, commercial, or not-for-profit sectors.

\section{Availability of data and materials}

The datasets used and/or analyzed during the current study data/materials will not be shared publicly or deposited in a repository link due to institutional regulations, however will be

available from the corresponding author on reasonable request.

\section{Declarations}

\section{Ethics approval and consent to participate}

Ethical clearance was obtained from the ethics review board (REB) of the Windsor Regional Hospital. Informed consent to participate was waived by the REB of Windsor Regional Hospital as the study is retrospective chart review and poses minimal risk to participants. The study was carried out in accordance with the relevant guidelines and regulations.

\section{Consent for publication}

Not applicable

\section{Competing interests}

No relevant conflict of interest for all authors.

\section{Author details}

'Windsor Regional Hospital, 2220 Kildare, WRCC, Windsor, ON N8W 2X3, Canada. ${ }^{2}$ London Health Sciences Center, Windsor, Canada.

\section{Received: 24 August 2021 Accepted: 19 January 2022}

Published online: 07 February 2022

\section{References}

1. Zhu Y, Tang K, Zhao F, Zang Y, Wang X, Li Z, et al. End-of-life chemotherapy is associated with poor survival and aggressive care in patients with small cell lung cancer. J Cancer Res Clin Oncol. 2018;144(8):1591-9.

2. Zhang Z, Chen ML, Gu XL, Liu MH, Zhao WW, Cheng WW. Palliative Chemotherapy Near the End of Life in Oncology Patients. Am J Hosp Palliat Care. 2018;35(9):1215-20.

3. Bao Y, Maciejewski RC, Garrido MM, Shah MA, Maciejewski PK, Prigerson HG. Chemotherapy Use, End-of-Life Care, and Costs of Care Among Patients Diagnosed with Stage IV Pancreatic Cancer. J Pain Symptom Manage. 2018;55(4):1113-21 e3.

4. Schulkes KJG, van Walree IC, van Elden LJR, van den Bos F, van HuisTanja L, Lammers JJ, et al. Chemotherapy and healthcare utilization near the end of life in patients with cancer. Eur J Cancer Care (Engl). 2018;27(2):e1s2796.

5. Norton SA, Wittink MN, Duberstein PR, Prigerson HG, Stanek S, Epstein RM. Family caregiver descriptions of stopping chemotherapy and end-oflife transitions. Support Care Cancer. 2019;27:669-75.

6. Matsuyama R, Reddy S, Smith TJ. Why do patients choose chemotherapy near the end of life? A review of the perspective of those facing death from cancer. J Clin Oncol. 2006;24(21):3490-6.

7. Rochigneux P, Raoul $\lrcorner$, Beaussant $Y$, Aubry R, Goldwasser F, Tournigand C, et al. Use of chemotherapy near the end of life: what factors matter? Ann Oncol. 2017;28(4):809-17.

8. Low D, Merkel EC, Menon M, Lyman GH, Ddungu H, Namukwaya E, et al. Chemotherapy Use at the End of Life in Uganda. J Glob Oncol. 2017;3(6):711-9.

9. Hui D, Park M, Liu D, Paiva CE, Suh SY, Morita T, et al. Clinician prediction of survival versus the Palliative Prognostic Score: Which approach is more accurate? Eur J Cancer. 2016;64:89-95.

10. Wu CK, Kao SJ, Lai HC. Targeted Therapy and Immunotherapy Lead to Rapid Regression of Advanced Non-Small Cell Lung Cancer with Multiple Driver Mutations. J Thorac Oncol. 2018;13(6):e103-e5.
11. Mathew A, Achkar T, Abberbock S, Sandhu GS, Jacob ME, Villgran VD, et al Prevalence and determinants of end-of-life chemotherapy use in patients with metastatic breast cancer. Breast J. 2017;23(6):718-22.

12. Liu TW, Chang WC, Wang HM, Chen JS, Koong SL, Hsiao SC, et al. Use of chemotherapy at the end of life among Taiwanese cancer decedents, 2001-2006. Acta Oncol. 2012;51(4):505-11.

13. Adam H, Hug S, Bosshard G. Chemotherapy near the end of life: a retrospective single-center analysis of patients' charts. BMC Palliat Care. 2014;13:26.

14. Mohammed AA, Al-Zahrani AS, Ghanem HM, Farooq MU, El Saify AM, El-Khatib HM. End-of-life palliative chemotherapy: where do we stand? J Egypt Natl Canc Inst. 2015;27(1):35-9.

15. Prigerson HG, Bao Y, Shah MA, Paulk ME, LeBlanc TW, Schneider BJ, et al. Chemotherapy Use, Performance Status, and Quality of Life at the End of Life. JAMA Oncol. 2015;1(6):778-84.

16. McCarthy M. Chemotherapy does not improve quality of life in cancer patients at end of life, US study finds. BMJ. 2015;351:h4139.

17. Ho TH, Barbera L, Saskin R, Lu H, Neville BA, Earle CC. Trends in the aggressiveness of end-of-life cancer care in the universal health care system of Ontario Canada. J Clin Oncol. 2011:29(12):1587-91.

18. Temel JS, Greer JA, Muzikansky A, Gallagher ER, Admane S, Jackson VA, et al. Early palliative care for patients with metastatic non-small-cell lung cancer. N Engl J Med. 2010;363(8):733-42.

19. Temel JS, Greer JA, Admane S, Gallagher ER, Jackson VA, Lynch TJ, et al. Longitudinal Perceptions of Prognosis and Goals of Therapy in Patients with Metastatic Non-Small-Cell Lung Cancer: Results of a Randomized Study of Early Palliative Care. J Clin Oncol. 2011;29(17):2319-26.

20. Parikh RB, Min EJ, Wileyto EP, Riaz F, Gross CP, Cohen RB, Hubbard RA, Long Q, Mamtani R. Uptake and Survival Outcomes Following Immune Checkpoint Inhibitor Therapy Among Trial-Ineligible Patients with Advanced Solid Cancers. JAMA Oncol. 2021. Volume 29, Number 17, June 10, 2011.

21. Suresh K, Voong KR, Shankar B, Forde PM, Ettinger DS, Marrone KA, et al. Pneumonitis in Non-Small Cell Lung Cancer Patients Receiving Immune Checkpoint Immunotherapy: Incidence and Risk Factors. J Thorac Oncol. 2018:13(12):1930-39.

\section{Publisher's Note}

Springer Nature remains neutral with regard to jurisdictional claims in published maps and institutional affiliations.

Ready to submit your research? Choose BMC and benefit from

- fast, convenient online submission

- thorough peer review by experienced researchers in your field

- rapid publication on acceptance

- support for research data, including large and complex data types

- gold Open Access which fosters wider collaboration and increased citations

- maximum visibility for your research: over $100 \mathrm{M}$ website views per year

At $\mathrm{BMC}$, research is always in progress.

Learn more biomedcentral.com/submissions 